\title{
МЕДИАТЕХНОЛОГИИ В КОРПОРАТИВНОЙ МОДЕЛИ МЕДИАОБРАЗОВАНИЯ: ВОЗМОЖНОСТИ И ПЕРСПЕКТИВЫ
}

\section{MEDIA TECHNOLOGIES IN CORPORATE MODEL OF MEDIA EDUCATION: OPPORTUNITIES AND PERSPECTIVE}

V. Yarnykh

Summary: The article examines the changes in the corporate training system under the influence of the appearance on the labor market of generations $Y$ and $X$, the digitalization of the educational environment and the need to develop transmedia literacy. These factors have led to significant changes in the corporate education system as a whole, and undoubtedly, under the influence of the COVID-19 infodemic, they are changing the corporate educational space. This makes it possible to talk about the formation and development of a corporate model of media education. In this regard, it is also necessary to talk about an expanded space for the use of modern media education technologies. Microlearning, mobile learning technologies, the development of transmedia literacy through the implementation of project activities are considered as an example of modern media educational technologies.

Keywords: media education, corporate model of media education, media education technologies, micro education, mobile education, transmedia literacy, project education, social media, theory of generations, generation $\mathrm{Y}$, generation $\mathrm{X}$, infodemic.

\section{Введение}

$\mathrm{M}$ ир сегодня - это мир медиа. Организации и люди существует сегодня в двух реальностях - виртуальной и реальной. В медийной и информационной среде необходимо присутствовать, существовать и развиваться. На рынке труда, да и на рынке обучения присутствует несколько поколений с разными запросами, разным опытом подготовки, разным пониманием того, как в принципе должно строится обучение. По сути, с разными ожиданиями. Эти факторы, да и стремительное изменение корпоративного мира в 2020 году в эпоху пандемии COVID-19 привели к существенным изменениям системы корпоративного образования и появлению новой модели корпоративного медиаобразования.

\section{Методология}

Статья написана на основе многолетней исследовательской, с точки зрения теории и практики рассматриваемой проблемы, деятельности автора. Использование комплекса взаимодополняющих теоретических и эмпирических методов исследования позволило по-
Ярных Вероника Игоревна

К.э.н., дочент, Российский Государственный Гуманитарный Университет vyarnykh@gmail.com

Аннотация: В статье рассматриваются изменения в системе корпоративного обучения под влиянием появления на рынке труда поколений $Y$ и $X$, дигитализацией образовательной среды и необходимостью развития трансмедиаграмотности. Эти факторы привели к существенным изменениям в системе корпоративного образования в целом, и безусловно под влиянием инфодемии COVID-19 изменяют корпоративное образовательное пространство. Это дает возможность говорить о формировании и развитии корпоративной модели медиаобразования. В этой связи также необходимо говорить о расширенном пространстве применения современных медиаобразовательных технологий. В качестве примера современных медиаобразовательных технологий рассматриваются микрообучение, мобильные технологии обучения, развитие трансмедиаграмотности через реализацию проектную деятельности.

Ключевые слова: медиаобразование, корпоративная модель медиаобразования, медиаобразовательные технологии, микрообучение, мобильное обучение, трансмедиаграмотность, проектное обучение, социальные медиа, теория поколений, поколение У, поколение X, инфодемия.

следовательно рассмотреть происходящие изменения в нестандартной ситуации этого года развития инфодемии COVID-19 в области корпоративного образования в целом, и в корпоративной модели медиаобразования в частности. Опора на имеющуюся источниковедческую базу, сопоставительно-сравнительный анализ, включенное наблюдение, позволяет интерпретировать происходящие события в контексте развития корпоративной модели медиаобразования.

\section{Сушествуюшие модели медиаобразования и преАпосылки Аля формирования корпоративной мохели медиаобразования}

Прежде всего необходимо отметить, что существует много моделей медиаобразования как такого. Подавляющее большинство этих моделей было разработано для школьного и вузовского образования, однако это не исключает использования подходов и понятий в других отраслях и секторах экономики. Представляется необходимым в рамках данной работы выделить следующие модели медиаобразования. Как отмечают Федоров А.В и Челышева И.В. разработанные в России модели 
медиаобразования можно разделить на образовательно-информационные (включающие изучение теории и истории, а также медиаязыка); воспитательно-этические (моральная, религиозная и философская проблематика на медиаматериале); практико-утилитарные модели (практическое изучение и применение медиасредств); эстетические (развитие художественного вкуса и анализ произведений медиакультуры) и модели развивающего обучения (главный акцент на развитие восприятия, воображения, критического мышления по отношению к медиатекстам любого типа и т.д.) [1, С. 34]. Важно отметить разнообразие подходов, факторов, систем, которые в том или ином виде используются при разработке моделей медиаобразования. Здесь же необходимо обратить внимание также на тот факт, что само понимание медиаобразования не является устоявшимся и закрепленным. Представляется необходимым с учетом современной ситуации и развития медийного пространства отметить, что ЮНЕСКО под медиаобразованием, например, рассматривает процесс развития личности с помощью и на материале средств массовой коммуникации (медиа) с целью формирования культуры общения с медиа, творческих, коммуникативных способностей, критического мышления, умений полноценного восприятия, интерпретации, анализа и оценки медиатекстов, обучения различным формам самовыражения при помощи медиатехники. Обретенная в результате этого процесса медиаграмотность помогает человеку активно использовать возможности информационного поля - телевидения, радио, видео, кинематографа, прессы, Интернета [2]. Медиаобразование сегодня существенно вышло за пределы школьного и вузовского образования, определение медиа грамотности как компетенции современного человека, необходимого ему для комфортного существования в современном мире заставляет и корпоративный сектор обращать внимание на данную проблему.

\section{Факторы изменения системы корпоративного образования в челом}

Инфодемия COVID-19 заставила корпоративный сектор быстрее приспосабливаться и пересматривать систему корпоративного образования. Однако и до весны 2020 года исследователи отмечали влияние нескольких факторов, которые внесли значительные корректировки в стратегию развития корпоративного образования. Основными причинами быстрых и существенных изменений в системе корпоративного образования стало стремительное развитие цифровых технологий, используемых в обучении, а также выход на рынок труда поколений, выросших в условиях проникновения цифровых технологий во все сферы жизни [3, С.502]. Если раньше мы заказывали продукты по телефону, теперь мы делаем это через приложения. Мы вынуждены использовать новые цифровые технологии, потому что по-другому просто невозможно существовать в современном мире.
Цифровые технологии существенно изменили образовательный ландшафт. Развитие цифровых технологий привело к появлению и развитию мобильного обучения, дистанционного обучения, e-learning. Но в целом необходимо говорить о смене образовательной парадигме. Это изменение не только в том, что процессы обучения переводятся в цифровую среду. Обучение в цифровую эпоху - это более глубокая трансформация всего процесса обучения, применение новых цифровых инструментов для переосмысления того, как необходимо обучать, чтобы быть современным. Обучение в цифровую эпоху уже сейчас носит непрерывный характер, выстраивается индивидуальная образовательная траектория в корпоративном формате, а образовательные решения в целом в некоторых компаниях уже сейчас принимаются на основании больших данных, формируя дальнейшую индивидуализацию обучения внутри корпорации. Однако говоря о корпоративной системе обучения важно принимать во внимание дальнейшие тренды развития корпоративного обучения в целом, базируясь на тех процессах, которые уже происходили до весны 2020 года. Прежде всего, это переход корпоративного обучения в онлайн. Это глобальный и безусловно самый очевидный тренд. Именно этот тренд развития корпоративного образования усугубился после ситуации инфодемии COVID-19 2020 года. Компании сами перешли в дистанционный, удаленный или смешанный формат работы, а такая смена форматов бизнес- процессов влечет за собой и смену форматов обучения.

Вторым безусловным трендом на сегодняшний день безусловно становится трансмедиаграмотность. 2020 год показал очень хорошо, что в корпоративном секторе становится важным повышать два вида грамотности цифровую и медийно-информационную. Вместе два вида грамотности позволяют говорить о трансмедиаграмотности как комплексном, обобщающем и интегрированном понятии [4, С.506]. Ситуация 2020 года не только в Российской Федерации, но и во всем мире продемонстрировала ситуацию инфодемии, то есть не просто информационный шум, к которому более - менее корпоративный сектор приспособился. Это потоковая волна фейков, домыслов, дезинформации, непроверенной информации о COVID-19. В этой ситуации переход на дистанционной формат работы и обучения вызвал не просто дополнительный стресс, а существенно затормозил поиск необходимой для работы или для учебы информации. При добавлении существенно выросшего информационного шума выяснилась необходимость критического мышления, умение анализировать входящую информацию, умение выделять важное и основное и т.д. Это навыки входящие в медийно-информационную компетентность. Вторым важным факторов в трансмедиаграмотности стало неумение работать на платформах и ресурсах для дистанционной работы или учебы. Выяснилось на практике, что сотрудники компаний отлично делают селфи и размещают ин- 
формацию в Instagram, но не умеют работать в сессионном зале в Zoome. Но точно такая же ситуация сложилась и в корпоративном секторе. Когда выяснилось, что и с корпоративными ресурсами для дистанционной работы (даже там, где такие ресурсы вроде бы были) сотрудники компании также работать не умеют. И это цифровая грамотность как составная часть трансмедиаграмотности. В этих условиях компании пришлось буквально на ходу перекраивать существующие корпоративные обучающие программы, и вводить новые.

Такой фокус на медийно-информационную и цифровую грамотность крупные корпорации в рамках системы корпоративного образования стали реализовывать и в процессе локдауна. Например, компания Норникель уже запустила проект «Цифровой Норникель». Программа рассчитана на два года; ее первый этап стартовал в середине апреля, второй запланирован на сентябрь текущего года. Сформированный цикл программ «Цифровой «Норникель» позволит всем сотрудникам выбрать необходимые курсы в онлайн обучении цифровой грамотности, развить соответствующие компетенции и повысить уровень квалификации [5].

И если раньше цифровая трансформация бизнеса шла последовательно и размеренно, то сегодняшняя ситуация вынуждает двигаться опережающими темпами. Основными компетенциями в сегодняшней ситуации практически одномоментно стали понимание основ кибербезопасности и медийной безопасности; понимание цифровых трендов; умение работать во внутренних коммуникациях внутри компании и умение пользоваться корпоративными ресурсами и продуктами. Главной компетенцией на сегодняшний момент становятся навыки управления проектами, причем проектами в дистанционном формате с распределённой командой проекта [6, C.2452].

Наконец третьим трендом, который фактически меняет образовательный ландшафт корпоративной образовательной системы, является наличие на рынке трех поколений $X, Y, Z$ со своими запросами и ожиданиями от корпоративного обучения и в инструментах, и в технологиях, и т.д. Именно поколение Үи Z стали драйверами для существенного расширения в использовании мобильного обучения, дистанционного обучения и т.д. Говоря о новых требованиях к принципам и технологиям корпоративного образования необходимо отметить следующее. Поколение Z в этом смысле определяет принципиальные изменения в системе корпоративного обучения. Прежде всего они являются цифровыми аборигенами, то есть людьми, с детства выросшими в цифровой среде. Это определяет «клиповость» или мозаичность их сознания; селективное восприятие - внимание только к тому, что соответствует ожиданиям; «пазл-поведение» - на основе разрозненных навыков и несвязанного практи- ческого опыта; свободное функционирование в цифровой среде [7, С.22]. С точки зрения технологий обучения это означает необходимость кодирования контента через визуализацию (картинка, инфографика отлично воспринимается), игровая форма занятий, необходимость выстраивать оперативное взаимодействие через цифровые коммуникации, и наконец необходимо поощрять даже самые маленькие достижения. Представители этого поколения нуждаются в самом небольшом, но постоянном поощрении в процессе обучения, поддержке их достижений, постоянного внимания к поддержанию образовательного трека. И в этой связи также необходимо принимать во внимание, что обучение для поколения Үи Z должно быть крайне практичным. Представители этих поколений, в отличие от поколения $\mathrm{X}$, должны очень хорошо понимать и представлять как полученные знания или отработанные навыки они будут применять в своей конкретной работе завтра. Вторым выводом в связи с требованиями поколений Z и Y становится запрос на очень короткие образовательные программы или курсы, ка уже отмечалось выше очень практичной направленности.

Суммируя предложенные выше факторы, существенно повлиявшие на коренные изменения в системе корпоративного образования, а таже отмечая выявленные проблемы инфодемии COVID -19 необходимо говорить, по сути, о следующих фокусах системы корпоративного образования в сегодняшних условиях. Это фокус на проектную работу и компетенции работы в распределённой среде, а также навыки работы под информационным давлением и в условиях многозадачности. Все это создает необходимость не только в перестройке подходов к системе корпоративного образования, но и совершенного нового взгляда на технологии и инструменты корпоративного обучения.

В сложившихся обстоятельствах важным представляется отметить тот факт, что данные факторы не просто являются драйверами изменений системы корпоративного образования. В данном случае важно говорить и об активном внедрении медиатехнологий в систему корпоративного обучения. Необходимо отметить, что корпоративный сектор безусловно является одним из наиболее восприимчивым к внедрению новых технологий, и конечно же, сложившаяся ситуация позволяет проанализировать организационную практику компаний.

Рассматривая медиаобразовательные технологии в целом важно отметить следующие моменты. Прежде всего это развитие цифровой образовательной корпоративной среды любой организации и образовательной в том числе. Это один из элементов управления корпоративными знаниями. Достаточное количество провайдеров предлагает сейчас корпоративные цифровые решения, по сути цифровые экосистемы, которые включают в 
себя разные структурные составляющие корпоративной системы. Важной структурной такой составляющей становятся, например, мобильные приложения. Мобильное обучение достаточно востребовано в последние несколько лет в корпоративном секторе. В данном случае мобильное приложение выступает в качестве точки доступа к корпоративной образовательной системе в целом. Необходимо обратить внимание на то, что мобильное приложение в корпоративной образовательной среде дает возможность реализовать концепт ЗА: любой контент в любое время и в любом месте. Мобильное приложение обеспечивает доступ к образовательному контенту тогда, когда удобно человеку и там, где удобно и комфортно. Медиаобразовательные технологии сосредоточены в системе в целом, и мобильные приложения дают возможность доступа к ним и использования в рамках образовательной программы. В отличие от традиционной формы подачи учебных материалов и заданий мобильное обучение применяет инновационные технологии, с помощью которых происходят изменения в процессе преподавания. Для доставки определенного рода информации применяются такие современные сервисы, как социальные сети, облачные хранилища, хостинги медиаданных, а в последнее время некоторые преподаватели стали использовать социальные сети, выкладывая туда полезную информацию. Исследователи ЮНЕСКО выделяют несколько ключевых факторов мобильного обучения [8, С. 15]. Прежде всего - это мобильность. Современные гаджеты дают возможность организовать и оптимизировать учебный процесс вне зависимости от места и времени. У такого рода мобильности существуют два аспекта: во-первых, возможность реализации образовательных программ несмотря на местоположение пользователя. Вторым важным фактором мобильного обучения становится непрерывность доступа к образовательному пространству, то есть реализация концепции 3А. Третьим фактором становится персонализация обучения и формирование индивидуальной образовательной траектории для каждого обучающегося. Мобильное обучение и мобильное приложение как точка доступа дают возможность на практике реализовать индивидуальный план обучения для каждого человека в зависимости от оценки результатов работы, потенциала и т.д. Еще одним фактором становится улучшение качества коммуникации. Мобильное приложение, связанное с мессенджерами, например, дает возможность коммуницировать одновременно всем участникам процесса, которые принимают участие в выбранной программе обучения. Также в этом случае есть возможность прямой коммуникации с преподавателем для уточнения рабочих вопросов и т.д. И наконец мобильные приложения дают возможность для реализации работы в проектной группе, устанавливая горизонтальные связи между обучающимися.

Работа в проектной группе как медиаобразователь- ная технология является одной из наиболее потенциальных для развития медиакомпетенций. Проектная группа как образовательная технология известна и используется достаточно давно. Однако работа над внутренним медиапроектом, например, позволяет развить комплекс коммуникационных, проектных, профессиональных и медиакомпетенций. Привычная деятельность в проекте удобна, понятна и комфортна для представителей поколения Z [9, С. 342]. Представители поколения Z, и частично представители поколения Y c детства играя в компьютерные игры привыкли к проектному поведению [10]. Это удобная медиаобразовательная технология для ведения образовательных проектов и является фактором мотивационных программ организации. Вторым важным фактором использования проектной работы как медиаобразовательной технологии позволяет использовать элементы менторинга и наставничества. А это один из возможных реализаций мотивационного фактора как статус внутри компании. Такие возможности позволяют реализовать комплексный подход в управлении человеческим капиталом компании.

Реализация собственных медиапроектов, работа с ними является важной современной медиаобразовательной технологией. Реализация собственных медиапроектов сотрудников достаточно распространена в образовательной организации любого уровня. Многие педагоги любого уровня имеют собственные медиапроекты (блоги, влоги, YouTube каналы, аккаунты в социальных сетях) нацеленные на профессиональную составляющую и демонстрирующие их портфолио, например. Кроме того, любой личный медиапроект сотрудника организации влияет на формирование медийного образа организации в целом. Например, негативные высказывания о компании или о конкурентах, провокационные фотографии или материалы, мгновенно тиражируются и распространяются в интернете, индексируются и влияют на паблисити компании. Важным фактором влияния на ситуацию в этом случае становится медийно-информационная грамотность сотрудников. Развитие элементов медийной, информационной и цифровой грамотности сотрудников включается в этом случае в образовательные корпоративные программы. Кроме того, в образовательные программы организации включаются и навыки работы с собственными медиапроектами, а также знания, умения их создания и продвижения в социальных медиа. Такой интегрированный подход позволяет комплексно подойти к решению подобных проблем. Как пример, можно привести программу, которую запустил Норникель в апреле 2020 года [5].

На апробированных примерах из корпоративного сектора можно сделать вывод, что медиаобразовательные технологии обладают огромным потенциалом для развития трансмедиаграмотности, и не только. 
Еще одним существенным изменением на рынке корпоративного образования в целом стало расширение использования микрообучения. Микрообучение (microlearning) - это способ представления новой информации малыми блоками, каждый из которых посвящен конкретной, очень узкой теме. Микрокурсы получили большую популярность именно в мобильном обучении [11]. Микрообучение в самом формате предполагает очень небольшие блоки контента с конкретными результатами. Более того, учитывая, что микрообучение используется в основном в мобильном обучении, необходимо обратить внимание на мультимедийность контента и мультиплатформенность его размещения. Курсы в формате микрообучения присутствуют на образовательных корпоративных мультиплатформах, они небольшие по объему, и дают возможность быстро получить результат. Это может быть и быстрое развитие какого-то навыка или умения, получение знаний и т.д.
Заключение. Инфодемия CVID - 19 стало мощным дополнительным драйвером развития системы корпоративного обучения. Использование в системе корпоративного обучения медиаобразовательных технологий позволяет решить несколько задач. Среди них и удовлетворение расширенных запросов стейкхолдеров обучения, и мотивация обучения для сотрудников, и возможности для быстрого развития навыков и умений. Компетенции траснмедиаграмотности стали ответом на вызов инфодемии и требуют развития с помощью совершенно новых технологий. Это и мобильное обучение, и микрообучение и развитие собственных медийных проектов сотрудников компаний.

И наконец важно отметить, что развитие медийных ресурсов сотрудников, и развитие траснмедиаграмотности также влияет на медиа имидж компании и существенно повышает ее шансы в конкуренции на рынке.

\section{ЛИТЕРАТУРА}

1. Федоров А.В., Челышева И.В. Медиаобразование в современной России: основные модели//Высшее образование в России. 2004. № 8. С.34-39.

2. Медиаобразование. Информация для всех. [Электронный ресурс]. URLIIhttps://ifap.ru/projects/mediaed2.htm (дата 0бращения 27.11.2020)

3. Zavyalova E.K., \& Ardichvili A. (2020). The Contemporary Problems of Corporate Education in Russian Companies: Can There Be Learning Without Development? Russian Management Journal, 17(4), 499-516. https://doi.org/10.21638/spbu18.2019.405

4. Гендина Н.И. Проблема интеграции информационной и медиаграмотности: Международный опыт и российские реалии। Вестник Кемеровского государственного университета культуры и искусств, N. 19-1, 2012, С. 54-71.

5. «НОРНИКЕЛЬ»: цифровой рывок в условиях самоизоляции.// Электрон. дан. URL https://www.nornickel.ru/news-and-media/press-releases-and-news/ nornikel-tsifrovoy-ryvok-v-usloviyakh-samoizolyatsii.htm (дата обращения 22.05.2020)

6. Falloon G. From digital literacy to digital competence: the teacher digital competency (TDC) framework. Education Tech Research Dev 68, 2020, P. $2449-2472$

7. Seemiller C., Grace M. Generation Z: Educating and Engaging the Next Generation of Students. About Campus. 2017, Volume 22(3), P. 21-26. doi:10.1002/abc.21293

8. Рекомендации по политике в области мобильного обучения. ЮНЕСКО. [Электронный ресурc].URLII https://iite.unesco.org/pics/publications/ru/ files/3214738.pdf (дата обращения 20.12.2020).

9. Якимова 3.В., Масилова М.Г. Поколение Z как потенциальный сегмент рынка труда // АНИ: педагогика и психология. 2017. №4 (21) С. $341-345$.

10. Кармазин T.B. Корпоративное обучение поколения Z. [Электронный ресурс]. URLIVhttps://ria-stk.ru/ds/adetail.php?ID=176525 (дата обращения 29.12.2020)

11. Глоссарий webinar academy. [Электронный ресурc]. URLIVhttps://academy.webinar.ru/glossary/mikroobuchenie (дата обращения 21.12.2020)

(c) Ярных Вероника Игоревна (vyarnykh@gmail.com) 